\title{
Population regulation in lake whitefish, Coregonus clupeaformis (Mitchill)
}

\author{
A. L. JENSEN \\ School of Natural Resources, University of Michigan, Ann Arbor, \\ Michigan 48109, U.S.A.
}

(Received 2 January 1981, Accepted 30 March, 1981)

\begin{abstract}
Mechanisms that might compensate for changes in mortality are well known but documentation of their operation and determination of their relative capacities is difficult. In this study the potential of lake whitefish to compensate for fishing mortality is quantified using a conventional fishery stock assessment model. The mechanisms examined are proportion of females, fecundity, survival of eggs and larvae, decrease in age at maturity and growth. The change in each of these parameters necessary to maintain constant recruitment with increasing fishing pressure is determined. Decrease in age of maturity and increased survival of larvae and eggs have the greatest potential for compensation. The total capacity for compensation appears large even when the mechanisms are considered alone. A review of several lake whitefish population studies indicates a large variation in the vital statistics. There is a close relation between total mortality and growth. There is also a close relation between growth and age at maturity. The analyses indicate that increased fishing results in increased growth which then results in a lower age at maturity. This feedback mechanism enables lake whitefish to respond to changes in environmental conditions and on average to maintain a birth rate in balance with mortality.
\end{abstract}

\section{INTRODUCTION}

Study of exploited populations provides an opportunity to examine how fish populations survive large fluctuations in mortality. Mechanisms that could operate to offset the impact of fishing mortality are well known, but documentation of their operation is difficult. In conventional stock assessment studies it is assumed that recruitment remains constant, but fishing has a large impact on the age structure and thus on the reproductive potential of exploited stocks and recruitment can remain constant only through density dependent compensation. The level of fishing that can be supported by a population depends on the extent to which various mechanisms are able to compensate for exploitation. In this study, the magnitude of change in the vital statistics necessary to compensate for fishing mortality is determined for lake whitefish, Coregonus clupeaformis. The impacts of fishing on population size, age structure and reproductive potential are reviewed and then the changes in growth rate, sex ratio, fecundity, age at maturity and survival of eggs and larvae necessary to compensate for different levels of exploitation are determined. A review of lake whitefish population studies provides estimates of the variation in vital statistics that might be available for compensation.

\section{REVIEW OF THE MODEL AND IMPACT OF FISHING}

The analytical model for stock assessment developed by Beverton \& Holt 557 
(1957) has been applied widely and its development and application are discussed in detail by Gulland (1969). The model separates yield into three componentsgrowth, reproduction and mortality. The equations for yield, numbers and individual weight are:

$$
\begin{aligned}
& \frac{\mathrm{d} Y}{\mathrm{~d} x}=F N W \\
& \frac{\mathrm{d} N}{\mathrm{~d} x}=-(F+M) N, \mathrm{x} \geqslant \mathrm{x}_{\mathrm{c}} \\
& \mathrm{d} N=-F N, x_{\mathrm{r}}<x<x_{c} \\
& \frac{\mathrm{d} W}{\mathrm{~d} x}=3 W_{\infty} K \mathrm{e}^{-K x}\left(1-\mathrm{e}^{-K(}\left(x-x_{0}\right)^{2},\right.
\end{aligned}
$$

where $Y=$ yield to the fishery; $F=$ instantaneous fishing mortality coefficient; $M=$ instantaneous natural mortality coefficient; $N=$ number of individuals of age $x$; $W=$ weight of an average individual of age $x ; W_{\infty}=$ average asymptotic weight; $K=$ growth parameter; and $x_{0}=$ theoretical age when length equals zero. Biomass of the exploited stock is given by the equation

$$
\mathrm{B}=\int_{x_{r}}^{\infty} N(x) W(x) \mathrm{d} x=R W_{\infty} \mathrm{e}^{-M\left(x_{c}-x_{r}\right)} \sum_{n=0}^{3} \frac{U_{n} \mathrm{e}^{-n K\left(x_{c}-x_{0}\right)}}{F+M+n K}
$$

where $U_{0}=1, U_{1}=-3, U_{2}=3$ and $U_{3}=-1$. In this study, equation (1) is used to relate biomass and fishing mortality.

Jensen (1979) applied the dynamic pool model for assessment of the lake whitefish stock in northern Lake Michigan. The parameter estimates obtained are summarized in Table $I$, which also lists estimates of several parameters not found in the biomass equation. These parameters are necessary for later simulations and include the number of eggs per unit of biomass, $E$, which was estimated as $17384 \mathrm{~kg}^{-1}$ (Cucin \& Regier, 1965); the duration of the egg stage $\Delta t_{1}$, and the duration of the larvae stage, $\Delta t_{2}$, which were estimated as 0.452 and 0.071 years respectively (Hart, 1930); and the age at maturity, $x_{m}$, which was estimated at age 4 in northern Lake Michigan (Patriarche, 1977). The number of recruits, $R$, was set at 1000 .

Exploitation causes substantial change in a population. The age structures of an unexploited population and an exploited population with the instantaneous fishing mortality coefficient at $F=0.60$ are shown in Fig 1 . Heavy exploitation reduces the number of older individuals in the population and these large fish produce large numbers of eggs. Exploitation results in a large decrease in the biomass of the standing stock (Fig. 2) and if egg production is assumed proportional to biomass, egg production follows the same pattern as biomass and decreases greatly with exploitation.

A more complete description of the impact of fishing on reproduction is given by the reproductive value, $V_{x^{\prime}}$ (Fisher, 1930) which is defined as

$$
V_{x}=\int_{x}^{w} \frac{l(t) m(t)}{l(x)} \mathrm{d} t
$$


TABLE I. Estimates of model parameters

\begin{tabular}{llc}
\hline \multicolumn{1}{c}{ Parameter } & Symbol & Value \\
\hline Asymptotic weight & $W_{\infty}$ & 3.50 \\
Instantaneous natural & & \\
$\quad$ mortality coefficient & $K$ & 0.40 \\
Growth parameter & $R$ & 0.30 \\
Recruitment & $x_{r}$ & 1000 \\
Recruitment age & $x_{0}$ & $4 \cdot 0$ \\
Age when length equals zero & $E$ & 0.01 \\
Eggs per unit biomass & $M_{1}$ & 17384 \\
Egg mortality coefficient & $M_{2}$ & $17 \cdot 75$ \\
Larvae mortality coefficient & $\Delta_{1}$ & 10.00 \\
Duration of egg stage (years) & $\Delta t_{2}$ & 0.453 \\
Duration of larvae stage (years) & $\Delta t_{3}$ & 0.077 \\
Duration of pre-recruit stage & $x_{m}$ & 3.471 \\
Age of maturity & $M_{3}$ & 4.0 \\
Pre-recruit mortality & & 0.55 \\
\hline
\end{tabular}

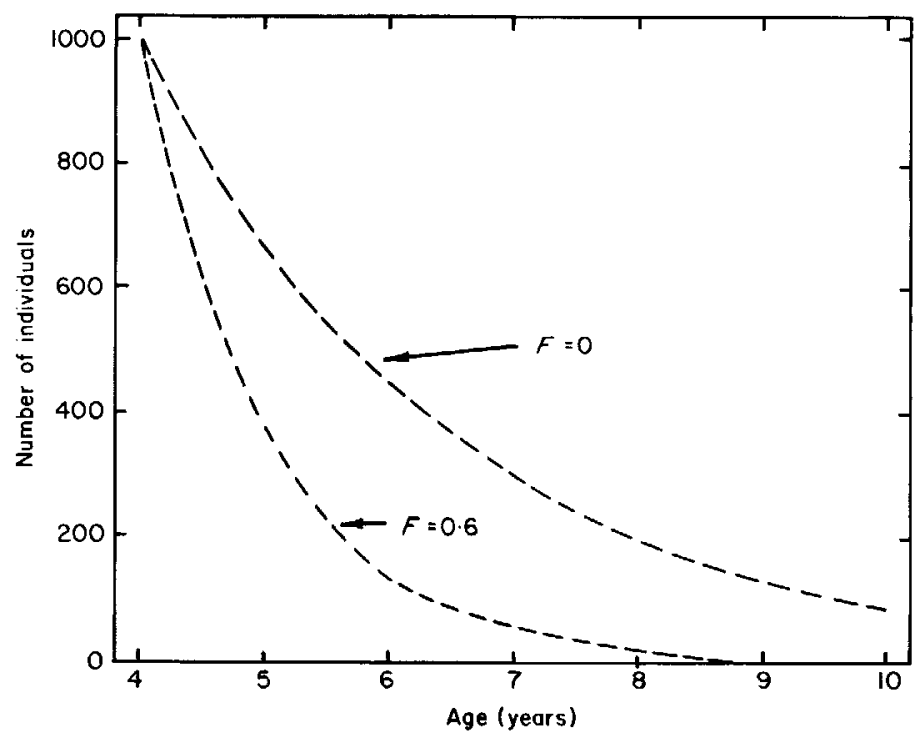

Fig. 1. Age structure of an unexploited and heavily exploited $(F=0.6)$ lake whitefish population showing the decrease in the number of older individuals with exploitation.

where $l(t)=$ probability of survival to age $t ; m(t)=$ number of eggs produced per female of age $t$ per year; and $w=$ oldest age attainable.

The reproductive value is the expected number of eggs that an individual of age $x$ will generate during the remainder of its lifetime. $V_{0}$ is the net reproductive rate. Under the assumption that egg production is proportional to weight, i.e. $m(t)=E \cdot W(t)$, and the assumption that growth and mortality are given by the Beverton \& Holt (1957) dynamic pool model, the reproductive value becomes 


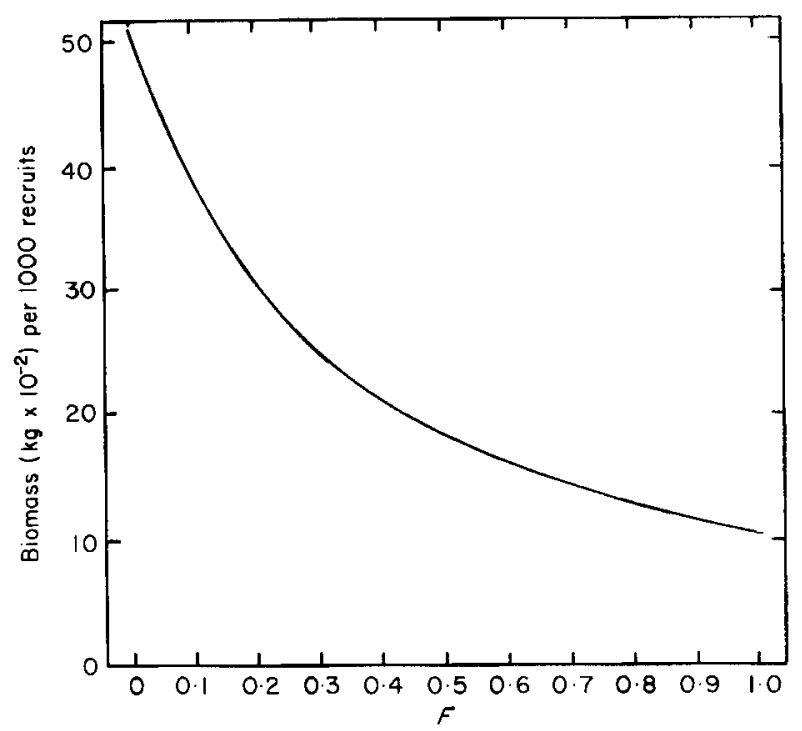

Fig. 2. Decrease in biomass of an exploited population with increase in fishing mortality.

$$
V_{x}=E W_{\infty} \sum_{n=0}^{3} \frac{U_{n} e^{-n K\left(x-x_{0}\right)}}{F+M+n K}\left[1-\mathrm{e}^{-(F+M+n K)(w-X)}\right]
$$

The above equation was applied to calculate $V_{x}$ over the lifespan under different levels of exploitation; the results are shown in (Fig. 3).

The expected number of eggs produced per individual increases asymptotically with age, but this increase in fecundity with age is balanced against a decrease in

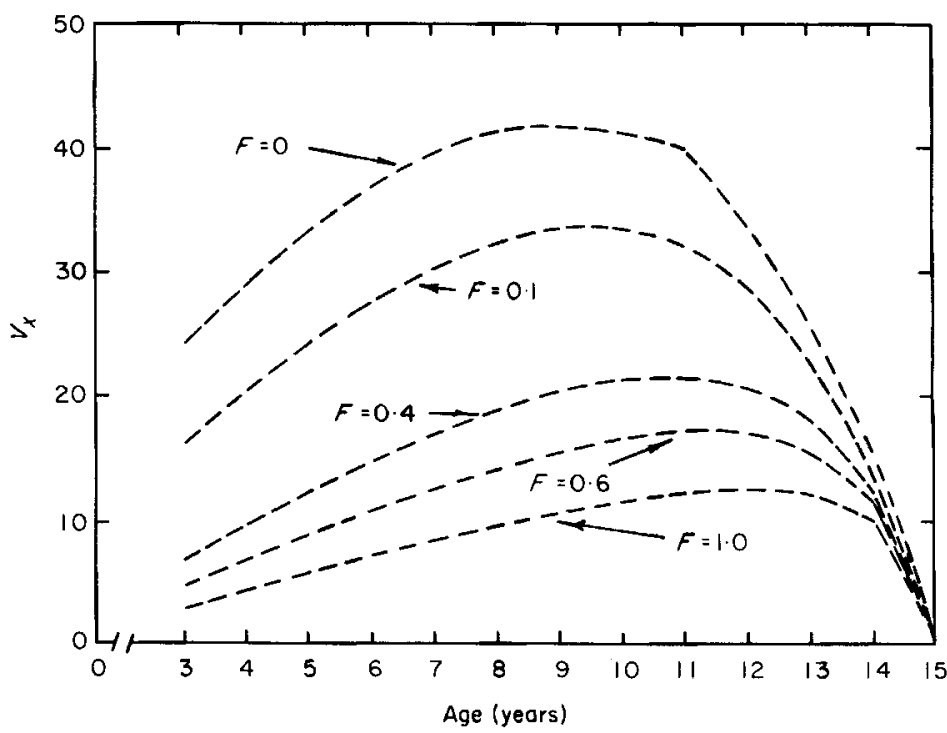

Fig. 3. Reproductive potential as a function of age for several fishing mortality coefficients. 
number of years of life remaining as the individuals grow older. With no exploitation the reproductive value increases to a maximum at about age 9 and then begins to decrease. Exploitation has a large impact on the reproductive potential of a fish population. The age at which the maximum reproductive value occurs is higher when fishing mortality is high because individuals do not live as long and the limitation of lifespan has less of an impact. The expected number of eggs that an individual will produce is reduced by fishing, e.g. the expected number of eggs that an individual of age 3 will produce is about 25 without a fishery and decreases to less than 5 with $F=0.60$. These changes in reproductive potential, that occur as a result of fishing, require that density dependent compensatory changes occur in the vital statistics to maintain a constant recruitment.

\section{POTENTIAL FOR COMPENSATION RESULTING FROM CHANGES IN VITAL STATISTICS}

The potential for possible compensatory mechanisms to maintain constant recruitment as fishing mortality is increased can be examined by determination of the change in the related variables necessary to maintain constant recruitment. The relation between recruitment and stock biomass is given by the equation

$$
R=p E B e^{-M_{1} \Delta t_{1}-M_{2} \Delta t_{2}-M_{3} \Delta t_{3}}
$$

where the only new symbol is the proportion of mature females, $p$. All terms are described in Table I. Equation (2) is the basis for calculation of the changes in vital statistics that are necessary to maintain a constant recruitment, $R$. An increase in fishing mortality will decrease the biomass of the mature stock. Biomass is calculated using the biomass equation [equation (1)]. The changes in the number of eggs per unit of biomass, egg mortality, larvae mortality and prerecruitment mortality necessary to maintain a constant number of recruits with the reduced biomass is determined.

As fishing mortality increases the number of recruits also could be maintained by an increase in the growth parameter and a decrease in the age of maturity which act to replace biomass of the mature stock lost to the fishery. These relations also are examined.

Solution of equation (2) for the proportion of females gives

$$
p=\frac{R \exp \left(M_{1} \Delta t_{1}+M_{2} \Delta t_{2}+M_{3} \Delta t_{3}\right),}{B E}
$$

in which $p$ is a function of $B$. Changes in biomass that result from changes in $F$ are calculated using equation (1). Application of the above equation shows that change in the proportion of females can compensate for only small changes in mortality of the exploited stock (Fig. 4). A population consisting nearly entirely of females could not compensate for the observed fishing mortality in northern Lake Michigan.

From equation (2), the relation between eggs per unit of biomass and biomass is

$$
E=\frac{R \exp \left(M_{1} \Delta t_{1}+M_{2} \Delta t_{2}+M_{3} \Delta t_{3}\right) .}{p B}
$$




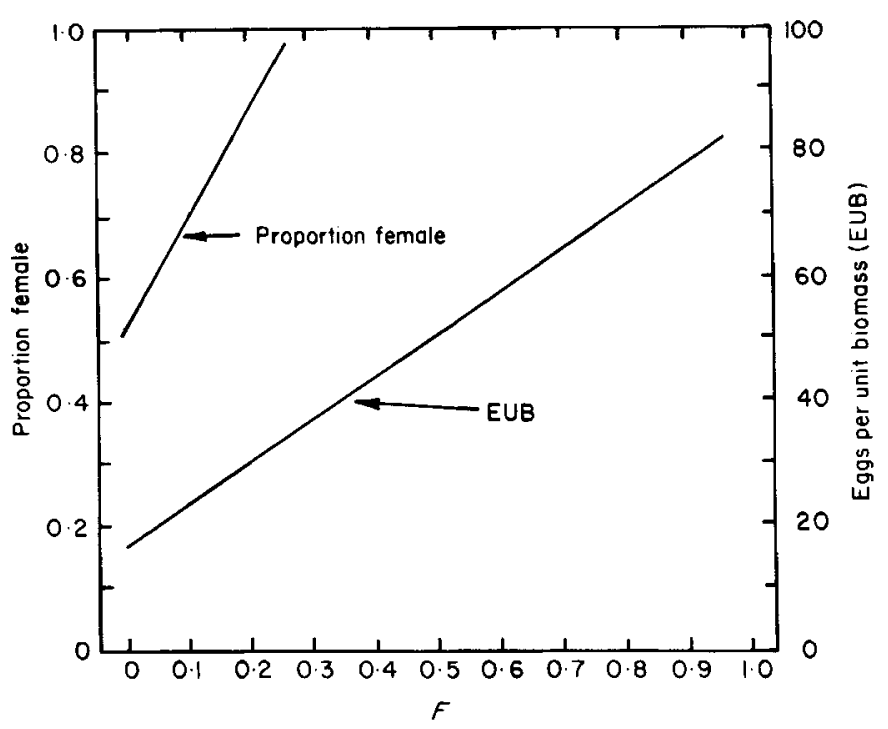

FIG. 4. Change in the proportion of females and number of eggs per unit of biomass necessary to compensate for fishing mortality.

Application of the above relation shows that change in number of eggs per unit of biomass also results in only a small capacity to compensate for exploitation (Fig. 4) given the observed range of eggs per unit of biomass (Table IV).

The combined egg and larvae mortality necessary to maintain a constant recruitment can be calculated but data for separation of this mortality into egg mortality and larvae mortality are not available. The partitioning of mortality between eggs and larvae has a large effect on the potential for compensation afforded by change in larvae mortality, so two cases are considered for both egg and larvae mortality. These two cases are high egg mortality with low larvae mortality and low egg mortality with high larvae mortality. If the instantaneous larvae mortality rate is assigned a value of 10 , the instantaneous egg mortality rate necessary to maintain constant recruitment is 17.75 . If the egg mortality rate is assigned a value of 10 , the larvae mortality rate necessary to maintain constant recruitment is 55.47 . This value seems unreasonably high; to maintain constant recruitment with low egg mortality a very high larvae mortality is necessary.

First, the relation between egg survival and fishing mortality is examined. From equation (2),

$$
M_{1}=\frac{-1}{\Delta t_{1}} \quad\left[M_{2} \Delta t_{2}+M_{3} \Delta t_{3}+\ln \left(\frac{R}{p B E}\right)\right]
$$

Application of this equation shows that change in egg mortality is potentially a powerful compensatory mechanism, whether egg mortality is high or lowl relative to larvae mortality (Fig. 5). The observed fishing mortality in northern Lake Michigan could be offset by a small decrease in egg mortality.

Egg mortality, as formulated in the model, consists of several separate factors that include: the proportion of mature females that spawn, the proportion of 


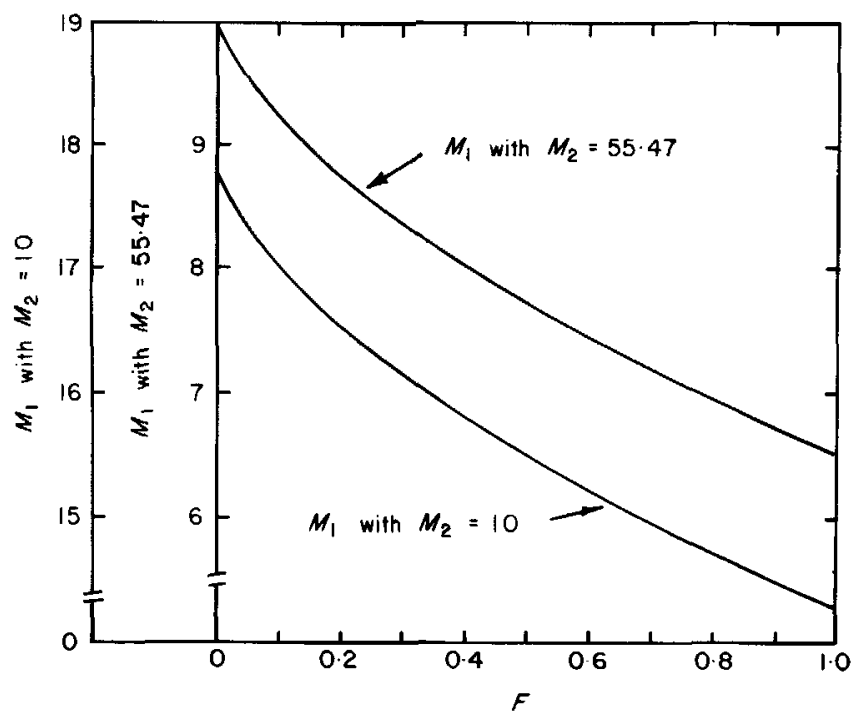

FIG. 5. Decrease in egg mortality necessary to compensate for fishing mortality. Curves are plotted for two different levels of egg mortality under exploited conditions $\left(M_{1}=17 \cdot 7\right.$ and $\left.M_{1}=10\right)$.

spawned eggs that are viable, the proportion of viable eggs fertilized and survival of fertilized eggs. For study of regulatory mechanisms, the impact of the first three factors alone is of interest. Survival of eggs can be written as

$$
\mathrm{e}^{-M_{1} \Delta t_{1}}=p_{1} p_{2} p_{3} \mathrm{e}^{-M_{1} \Delta t_{1}},
$$

where $p_{1}=$ proportion of mature females that spawn; $p_{2}=$ proportion of eggs produced that are viable; $p_{3}=$ proportion of viable eggs fertilized and $M_{1}^{\prime}=$ egg mortality coefficient adjusted for the above factors.

The three proportions above were combined into one proportion denoted as $p_{s}$. The relation between this proportion and biomass is

$$
p_{s}=\frac{R \exp \left(M_{1}^{\prime} \Delta t_{1}+M_{2} \Delta t_{2}+M_{3} \Delta t_{3}\right) .}{p B E}
$$

The value of $p_{s}$ without exploitation was set at 0.075 , which occurs if in an unexploited population $p_{1}=0.50, p_{2}=0.50$ and $p_{3}=0.30$. These are reasonable values for $p_{1}$ and $p_{3}$ (Van Oosten, 1956; Hart, 1930; Kennedy, 1953; Quadri, 1955). Values for $p_{2}$ have not been reported. These three factors acting together have a substantial potential for compensation (Fig. 6).

For larvae mortality, from equation (2), solving for $M_{2}$ gives

$$
M_{2}=\frac{-1}{\Delta t_{2}} \quad\left[M_{1} \Delta t_{1}+M_{3} \Delta t_{3}+\ln \left(\frac{R}{p E B}\right)\right] .
$$

Application of the above equation indicates that if egg mortality is high compared to larvae mortality, change in larvae mortality affords little compensation for an increase in exploitation (Fig. 7). If egg mortality is 


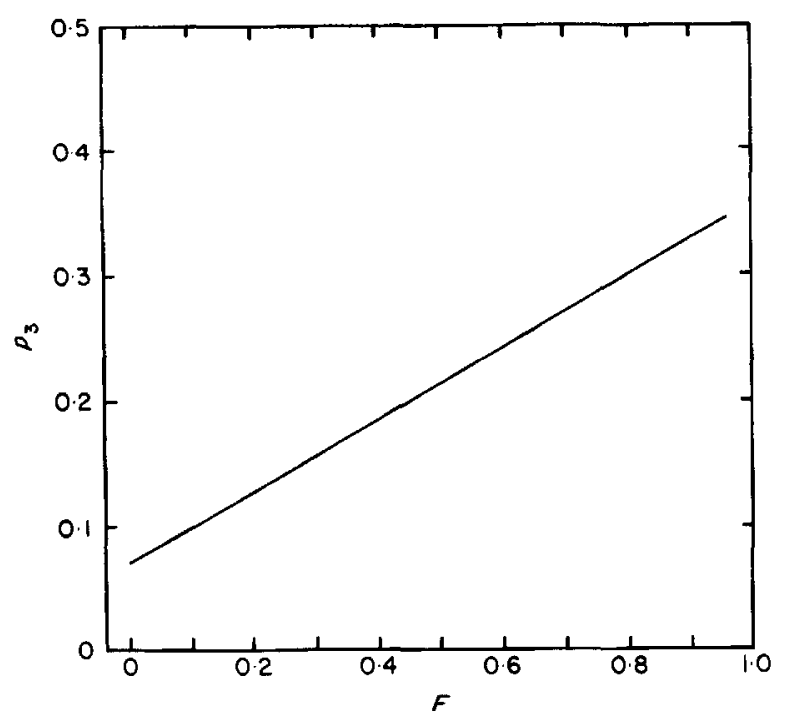

FIG. 6. Increase in the combined proportion $p_{3}$, which is the proportion spawning $\times$ proportion of viable eggs $\times$ proportion of eggs fertilized, necessary to compensate for fishing mortality.

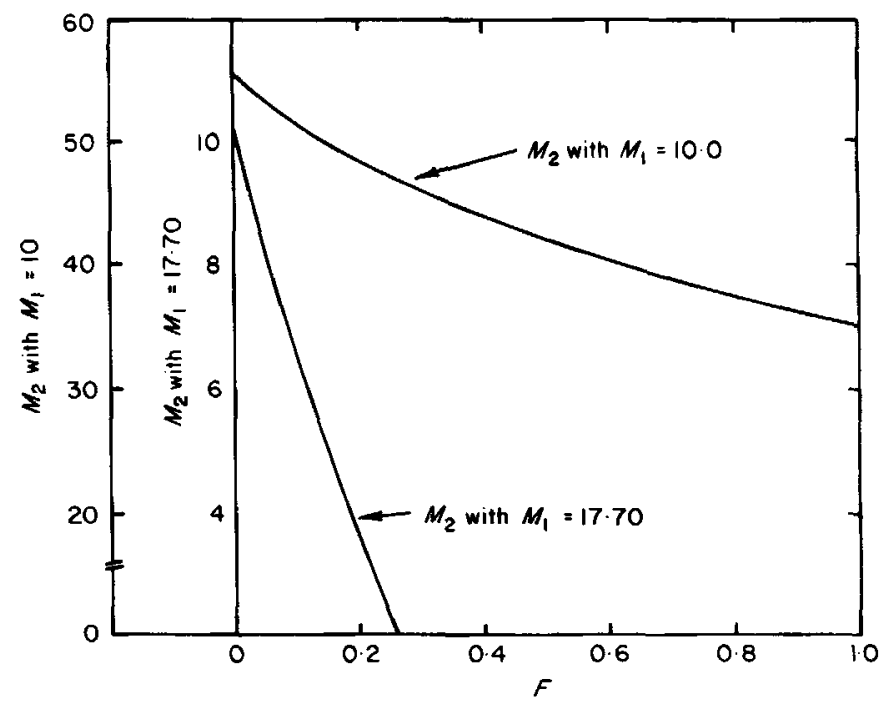

Fig. 7. Decrease in larvae mortality necessary to compensate for fishing mortality. Curves are plotted for two different levels of mortality under unexploited conditions $\left(M_{2}=10\right.$ and $\left.M_{2}=55 \cdot 57\right)$.

low compared to larvae mortality, change in larvae mortality becomes a potentially powerful compensatory mechanism (Fig. 7).

Change in age at maturity increases the biomass of the spawning stock to offset the biomass lost to the fishery. If the age at maturity is larger than the age at entry into the fishery, which is true for lake whitefish, the biomass of the mature stock, denoted as $B\left(F, x_{m}\right)$, is given by 


$$
B\left(F, x_{m}\right)=\int_{x_{m}}^{\infty} N(x) W(x) \mathrm{d} x
$$

which, after substitution for $N(x)$ and $W(x)$ and integration gives

$$
B\left(F, x_{m}\right)=W_{\infty} R \exp \left[-M\left(x_{c}-x_{r}\right)-(F+M)\left(x_{m}-x_{c}\right)\right] \sum_{n=0}^{3} \frac{U_{n} \mathrm{e}^{-n K\left(x_{m}-x_{0}\right)}}{F+M+n K} .
$$

The above equation cannot be solved to express the age at maturity, $x_{m}$, in terms of $F$, so for a range of $F$ values Newton's method was applied to find a value of $F$ such that $B\left(F, x_{m}\right)-B\left(O, x_{m}^{\prime}\right)=0$, where $x_{m}^{\prime}$ is the age of maturity without fishing. Change in age at maturity is potentially a powerful compensatory mechanism (Fig. 8).

Change in the growth rate also increases the biomass of the mature stock. The biomass equation [equation (1)] cannot be solved to express the growth rate, $K$, as a function of fishing mortality so Newton's method was applied to calculate $F$ for a range of $K$ values such that $B\left(O, K^{\prime}\right)-B(F, K)=O$, where $K^{\prime}$ is the growth coefficient without a fishery. Assuming $K^{\prime}=0 \cdot 20$, change in the growth rate alone could compensate for a low rate of exploitation (Fig. 8).

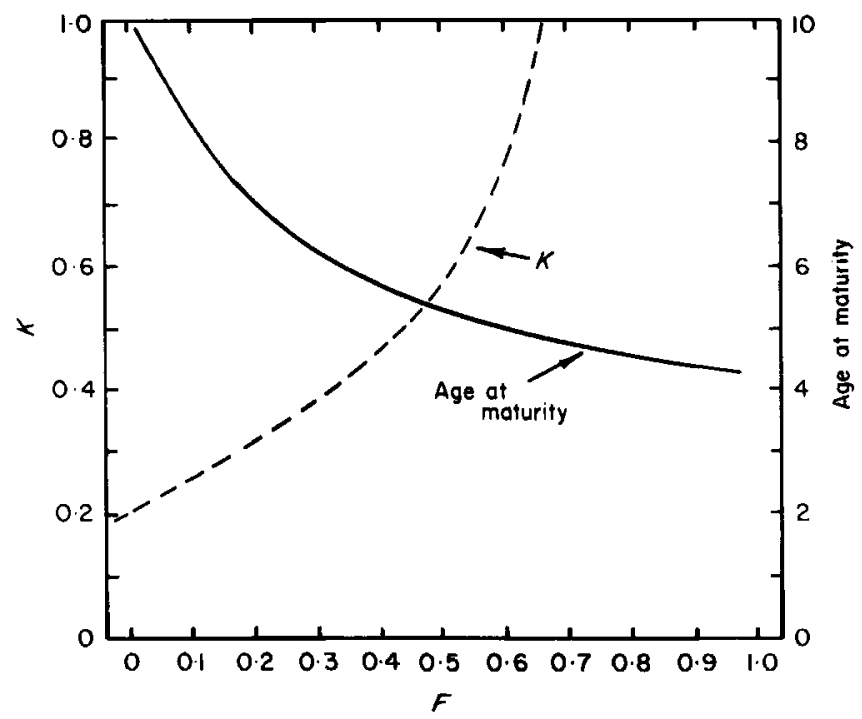

Fig. 8. Increase in the growth rate and decrease in the age of 50\% maturity of females necessary to compensate for fishing mortality.

\section{DISCUSSION}

Exploitation causes large changes in the age structure and reproductive potential of a population. Density dependent compensatory mechanisms operate to maintain the balance of recruitment and mortality. Annual mortality rates for 
lake whitefish range from 0.06 to $82 \%$ (Table II). Yet all of these populations sustain themselves-they neither increase without limit nor become extinct. Studies of lake whitefish populations from widely different environments (references cited in Tables II, III, IV \& V) indicate three different population types. In heavily exploited populations from large lakes the values of $K$ are intermediate, asymptotic lengths are high and lengths at maturity are high, but ages at maturity are low. In large northern lakes with unexploited populations the values of $K$ are low, asymptotic lengths are low and ages at first maturity are high. Populations in highly exploited small lakes have high $K$ values, early ages at maturity and lower asymptotic lengths than populations in unexploited large lakes. In all environments, exploitation is associated with faster growth and an earlier age at maturity.

Exploitation reduces intraspecific competition and results in faster growth (Healy, 1980). Rapid growth of individuals under the favourable conditions produced by exploitation could trigger mechanisms that might exist to produce more female offspring. Under heavy exploitation a substantial increase in the proportion of females was reported for chubs, Coregonus hoyi, in Lake Michigan, a species closely related to lake whitefish (Brown, 1970). The observed proportions of females among many populations of lake whitefish (Table III) indicates a high variation but changes in the proportion of females over the proportions observed could compensate little for exploitation. This is not an important mechanism.

Increase in the growth rate alone could result in only a small degree of compensation (Fig. 8) and the observed variation in growth rate indicates that change in growth alone cannot be an important compensatory mechanism. However, an increase in the grwoth rate is related to increased fecundity and a lower age at maturity. Fecundity is easy to measure and it has been extensively studied.

Better conditions for growth, produced by a decrease in intraspecific competition resulting from exploitation, do produce a higher age specific fecundity in lake whitefish (Healey, 1980). Several laboratory studies have shown that egg production is related to the ration of the adults for a range of fish species. Bagenal (1969) showed that increased food consumption resulted in increased fecundity of brown trout, Salmo trutta, Wootton (1973) demonstrated that a higher ration produced an early age at maturity, a larger proportion of spawners and a higher age specific fecundity in stickleback, Gasterosteus aculeatus. Size or weight of eggs did not change. Smith et al. (1978) found increased fecundity and larger eggs in fathead minnows, Pimephales promelas, fed larger rations. Larger females produced larger eggs. Schoenherr (1977) showed fecundity of gila topminnows, Poeciliopsis occidentalis, increased with food supply. In lake whitefish there is a wide range in egg production per unit of biomass (Table IV) but change in fecundity can provide only a small capacity to compensate for exploitation (Fig. 4). Change in fecundity is not an important compensatory factor in lake whitefish.

There is much variation in the age of maturity among various stocks of lake whitefish (Table VI). The age at which $50 \%$ of females mature varies from ages 2.5 to 11 . The two unexploited populations have ages of $50 \%$ female maturity of 11 and $9 \cdot 2$, whereas the heavily exploited stocks in the Great Lakes have an age of $50 \%$ maturity of about 3 or 4 (Table VI). Among 14 populations for which data 
TABLE II. Total mortality rates, $Z$, for several exploited and unexploited lake whitefish populations

\begin{tabular}{|c|c|c|c|}
\hline Locality & $Z$ & Exploited & Reference \\
\hline Shakespeare Lake & $0 \cdot 20$ & no & Ricker (1947) \\
\hline Lake Superior & $0 \cdot 30^{*}$ & no & Edsall (1960) \\
\hline Lake Nipigon & 0.45 & no & Ricker (1947) \\
\hline Great Bear Lake & 0.54 & no & Kennedy (1949) \\
\hline Hottah Lake & 0.62 & no & Wong \& Whillans (1973) \\
\hline Lake Opeongo & $0.65^{*}$ & no & Ricker (1947) \\
\hline Alexie Lake & 0.65 & no & Healey (1975) \\
\hline Chitty Lake & $0 \cdot 78$ & no & Healey (1975) \\
\hline Baptiste Lake & $0 \cdot 82$ & no & Healey (1975) \\
\hline Drygeese Lake & 0.82 & no & Healey (1975) \\
\hline Nueltin Lake & $0 \cdot 84$ & no & Kennedy (1963) \\
\hline MacEwan Lake & $1 \cdot 35$ & no & Kennedy (1963) \\
\hline Lake La Ronge & 0.69 & yes & Quadri (1968) \\
\hline Lake Ontario & $0 \cdot 73$ & yes & Christie (1963) \\
\hline Great Slave Lake & $0 \cdot 84^{*}$ & yes & Kennedy (1953) \\
\hline Great Slave Lake & $0.87^{*}$ & yes & Bond \& Turnbull (1973) \\
\hline Buck Lake & $0 \cdot 89$ & yes & Bidgood (1972) \\
\hline Red Lakes & 0.65 & yes & Peterka \& Smith (1970) \\
\hline Lake Winnipeg & 0.51 & yes & Kennedy (1954) \\
\hline Lake Winnipeg & $1 \cdot 56$ & yes & Davidoffet al. (1973) \\
\hline Lake La Martre & $1 \cdot 05$ & yes & Bond (1973) \\
\hline Lake Huron & 0.97 & yes & Cucin \& Regier (1965) \\
\hline Lake Huron & $1 \cdot 47$ & yes & Budd (1956) \\
\hline Pigeon Lake & $1 \cdot 08$ & yes & Bidgood (1972) \\
\hline Pigeon Lake & $1 \cdot 39 *$ & yes & Miller (1947) \\
\hline Lake Erie & $1 \cdot 24$ & yes & Van Oosten \& Hile-(1947) \\
\hline Lake Erie & $1 \cdot 35$ & yes & Lawler (1965) \\
\hline Lake Huron & 0.82 & yes & Budd (1956) \\
\hline Lake Huron & $2 \cdot 21$ & yes & Spangler (1970) \\
\hline Lake Huron & $2 \cdot 66$ & yes & Budd \& Cucin (1962) \\
\hline Lake Michigan & $2 \cdot 81$ & yes & Roelofs (1958) \\
\hline Lake Michigan & $1 \cdot 00^{*}$ & yes & Jensen (1979) \\
\hline
\end{tabular}

*Mortality rates applied together with corresponding growth rates of Table $\mathrm{V}$ to estimate regression equation parameters (Fig. 10).

TABLE III. Female proportions of spawning stocks of lake whitefish

\begin{tabular}{lcl}
\hline \multicolumn{1}{c}{ Location } & Proportion & \multicolumn{1}{c}{ Reference } \\
\hline Shakespeare Lake & 0.46 & Hart (1931) \\
Great Slave Lake & 0.51 & Kennedy (1953) \\
Lake La Ronge & $0.48-0.51$ & Quadri (1968) \\
Lesser Slave Lake & $0.37-0.69$ & Bell et al. (1977) \\
Lake Superior & $0.48-0.86$ & Dryer (1964) \\
Lake Superior & $0.50-0.55$ & Edsall (1960) \\
Lake Erie & $0.41-0.57$ & Van Osten \& Hile (1947) \\
Trout Lake, WI & 0.62 & Hile \& Deason (1934) \\
\hline
\end{tabular}


on growth rates and age at maturity are available, there is a close relation between these variables (Fig. 9). The equation

$$
x_{m}=-1.73-3.85 \ln K
$$

fits these data well. The regression is significant $(P<0.0012)$ with a coefficient of determination of $R^{2}=0 \cdot 60$. On the average, an increase in the growth rate results in a lower age at maturity. For six populations for which data are available (Tables II, V) there is also a close relation between the total mortality rate and the growth rate (Fig. 10). The equation

$$
\ln K=-3 \cdot 15+1 \cdot 75 Z
$$

fits these data well. The regression is significant $(P<0 \cdot 008)$ and the coefficient of determination is $R^{2}=0.86$. These results indicate that over a wide range of environments an increase in the total mortality rate results in a higher rate of growth which results in an earlier age at maturity. This same result was reported for brook trout, Salvelinus fontinalis (Jensen, 1971).

A decrease in the age of maturity from 10 to 4 or 5 will offset a large increase in fishing mortality (Fig. 8). The entire fishing mortality experienced by whitefish in northern Lake Michigan could be more than offset by a decrease in age at maturity if the age at maturity was 10 in the absence of a fishery. Change in age at maturity is potentially a powerful compensatory mechanism and observed variation in age at maturity (Table VI) indicates that this may in fact be an important mechanism.

In the fisheries literature, a decrease in larvae mortality is assumed to be the major mechanism of compensation for exploitation (Beverton \& Holt, 1957). This does not appear to be the case for lake whitefish. Under reasonable conditions of high egg mortality and low larvae mortality, change in larvae mortality can compensate little for fishing (Fig. 7). Change in egg mortality has a

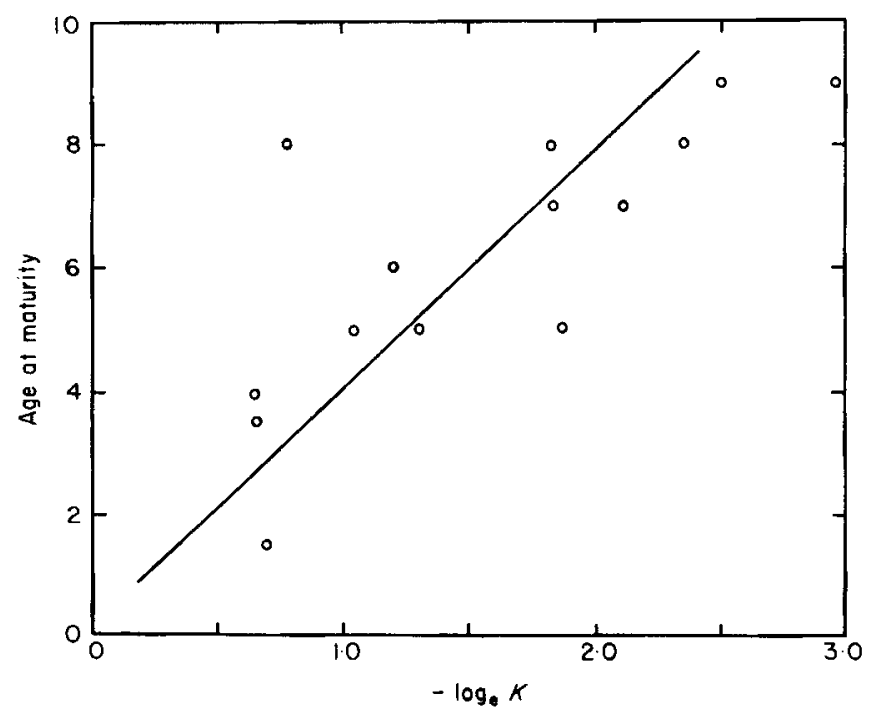

Fig. 9. Relation between growth coefficient and the earliest age at maturity for several populations of lake whitefish. 


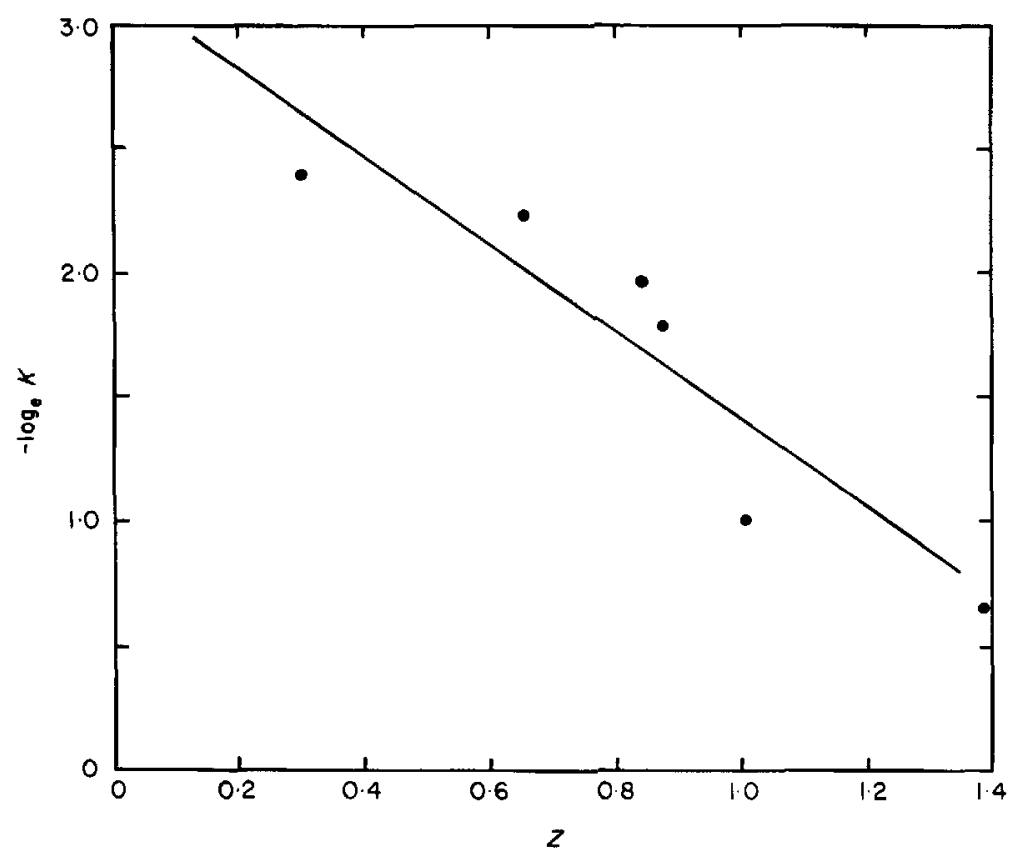

FIG. 10. Relation between instantaneous total mortality rate and growth coefficient (data from Tables II, V).

much larger potential for compensation than change in larvae mortality, even when egg mortality is low.

Egg mortality was separated into several components. One component is the actual survival of the fertilized eggs. The remaining components are the proportion of females spawning, viability of eggs and percentage of eggs fertilized. This second group of components can be influenced by the conditions of growth experienced by adult whitefish. There is considerable variation in these components. In two studies, successful fertilization ranged from 30 to $100 \%$ (Van Oosten, 1956) and from 62 to $100 \%$ (Hart, 1930). Kennedy (1953) and Quadri (1955) reported that about $50 \%$ of mature females spawned annually in unexploited populations. Assuming that under unexploited conditions $p_{1}=0.5$,

TABLE IV. Egg production per unit of female biomass of lake whitefish

\begin{tabular}{lcl}
\hline \multicolumn{1}{c}{ Location } & $\begin{array}{c}\text { Eggs per Unit } \\
\text { Biomass }\left(\mathbf{k g} \times 10^{\mathbf{3}}\right)\end{array}$ & \multicolumn{1}{c}{ Reference } \\
\hline Lake Ontario & 21.8 & Christie (1963) \\
Lake Erie & 34.3 & Lawler (1961) \\
Lake Huron & 17.0 & Cucin \& Regier (1965) \\
Lake La Ronge & 15.8 & Quadri (1968) \\
Hunter Bay & 19.9 & Quadri (1968) \\
Small Alberta Lake & 18.0 & Bidgood (1973) \\
Small Alberta Lake & 27.7 & Bidgood (1973) \\
\hline
\end{tabular}


TABLE V. Parameters for the von Bertalanffy growth equation for several different lake whitefish populations

\begin{tabular}{lcccl}
\hline \multicolumn{1}{c}{ Locality } & $W_{\infty}$ & $K$ & $x_{0}$ & \multicolumn{1}{c}{ Reference } \\
\hline Lake Superior & $2 \cdot 75$ & $0 \cdot 09$ & $-2 \cdot 3$ & Edsall (1960) \\
Green Bay & $3 \cdot 37$ & $0 \cdot 31$ & $0 \cdot 1$ & Mraz (1964) \\
Lake Michigan & $4 \cdot 7-5 \cdot 32$ & $0 \cdot 20$ & $0 \cdot 2-0 \cdot 3$ & Mraz (1964) \\
Lake Superior & $1 \cdot 87$ & $0 \cdot 32$ & $-0 \cdot 7$ & Dryer(1964) \\
Lake Superior & $4 \cdot 67$ & $0 \cdot 26$ & $-0 \cdot 2$ & Dryer (1964) \\
Lake Superior & $5 \cdot 14$ & $0 \cdot 24$ & $-0 \cdot 9$ & Dryer (1964) \\
Lake Superior & $3 \cdot 25$ & $0 \cdot 28$ & $-0 \cdot 9$ & Dryer (1964) \\
Lake Michigan & $2 \cdot 40$ & $0 \cdot 42$ & $0 \cdot 9$ & Brown (1968) \\
Lake Michigan & $3 \cdot 43$ & $0 \cdot 31$ & 0 & Brown (1968) \\
Lake Michigan & $3 \cdot 80$ & $0 \cdot 30$ & 0 & Brown (1968) \\
Pigeon Lake & - & $0 \cdot 52$ & $0 \cdot 5$ & Miller (1949) \\
Lake Wabamum & - & $0 \cdot 42$ & $0 \cdot 5$ & Miller (1949) \\
Great Slave Lake & - & $0 \cdot 14$ & - & Kennedy (1953) \\
Great Slave Lake & - & $0 \cdot 17$ & - & Bond \& Turnbull (1973) \\
Trout Lake & - & $0 \cdot 10$ & - & Hile \& Deason (1934) \\
Great Bear Lake & - & $0 \cdot 09$ & - & Kennedy (1949) \\
Lake Openongo & - & $0 \cdot 11$ & - & Kennedy (1943) \\
Cliff Lake & - & $0 \cdot 18$ & - & Fenderson (1964) \\
Lake Openongo & - & $0 \cdot 61$ & - & Kennedy (1943) \\
Cliff Lake & - & $0 \cdot 96$ & - & Fenderson (1964) \\
\hline
\end{tabular}

TABLE VI. Age at maturity for lake whitefish females

\begin{tabular}{lccl}
\hline \multicolumn{1}{c}{ Locality } & $\begin{array}{c}\text { Earliest } \\
\text { age }\end{array}$ & $\begin{array}{c}\text { Age when } \\
50 \% \text { mature }\end{array}$ & \multicolumn{1}{c}{ Reference } \\
\hline Great Bear Lake & 6 & $6 \cdot 8$ & Kennedy (1949) \\
Great Slave Lake & 4 & 6 & Healey (1975) \\
Lake Opeongo & 2 & 4 & Kennedy (1943) \\
Cliff Lake & 3 & $5 \cdot 2$ & Fenderson (1964) \\
Clear Lake & 4 & 4 & Fenderson (1964) \\
Great Slave Lake & 5 & $9 \cdot 2$ & Kennedy (1953) \\
Lesser Slave Lake & 4 & $6 \cdot 0$ & Bell et al. (1977) \\
Lake Superior & 5 & $6 \cdot 2$ & Dryer (1964) \\
Lake Superior & $10 \cdot 0$ & 11 & Edsall (1960) \\
Lake Michigan & - & $4 \cdot 2$ & Brown (1968) \\
Lake Michigan & 2 & $2 \cdot 5$ & Brown (1968) \\
Green Bay & 3 & 3 & Mraz (1964) \\
Lake Erie & 3 & 3 & Van Oosten \& Hile (1947) \\
Lake Huron & 3 & 6 & Van Oosten (1939) \\
Lake Opeongo & 1 & 1 & Kennedy (1943) \\
Cliff Lake & 1 & 1 & Fenderson (1964) \\
& & & \\
\hline
\end{tabular}


$p_{2}=0.5$ and $p_{3}=0.3$, change in these parameters has a large potential for compensation (Fig. 6).

If population size is regulated by conditions of growth in the mature stock, it is necessary for compensation to occur through factors other than survival of eggs and larvae. Unless production of young is so great that crowding or cannibalism are important factors, the conditions experienced by adult fish should not impact on mortality rates of eggs and larvae.

Except for larvae and egg mortality, the mechanisms of compensation examined here are related to the conditions of growth of the mature stock. This creates a feedback mechanism for regulation of population size relative to the availability of resources for growth of individuals in the mature stock. For example, because age at maturity is dependent on size there is feedback between the mortality rate, which acts on growth, and reproduction. Increased mortality reduces intraspecific competition and increases growth which results in a younger age at maturity and perhaps an increased age specific fecundity. A favourable environment for growth of mature females also might result in higher quality eggs, a greater proportion of females spawning and a larger number of fertilized eggs. These factors acting alone or together, without aid of a decrease in larvae or egg mortality, could more than compensate for the observed level of fishing in northern Lake Michigan. These mechanisms would provide whitefish with a mechanism to respond quickly to changes in the environment that either enhance or diminish the conditions for growth.

This work was funded by the Michigan Sea Grant Program.

\section{References}

Bagenal, T. B. (1969). The relationship between food supply and fecundity in brown trout Salmo trutta. J. Fish Biol. 1, 167-182.

Bell, G., Handford, P. \& Dietz, C. (1977). Dynamics of an exploited population of lake whitefish (Coregonus clupeaformis). J. Fish. Res. Bd Can. 34, 942-953.

Beverton, R. J. H. \& Holt, S. J. (1957). On the dynamics of exploited fish populations. Fishery Invest., Lond. (Ser. 2) 19, 533 pp.

Bidgood, B. F. (1972). Divergent growth in the lake whitefish populations from two eutrophic Alberta lakes. Alberta Fish. Wildl. Div. Fish. Sect. Res. Rep. 9, 1-121.

Bidgood, B. F. (1973). Divergent growth in two lake whitefish populations. J. Fish. Res. Bd Can. 30, 1683-1696.

Bond, W. A. (1973). An investigation of the commercial fishery at Lac la Marte, Northwest Territories. 1972. Fish. Mar. Serv. Tech. Rep. Ser. CENT-75-5. 49 pp.

Brown, R. (1968). Whitefish in Lake Michigan. MS Thesis. University of Michigan (unpublished) $61 \mathrm{pp}$.

Brown, E. H., Jr. (1970). Extreme female predominance in the bloater (Coregonus hoyi) of Lake Michigan in the 1960 s. In Biology of Coregonis fishes (C. C. Lindsey \& C. S. Wood, eds), pp. 501-514. Winnipeg: Manitoba Press.

Budd, J. (1956). Movements of tagged whitefish in northern Lake Huron and Georgian Bay. Trans. Am. Fish. Soc. 86, 128-134.

Budd, J. \& Cucin, D. (1962). Exploitation of Canadian Lake Huron whitefish. Trans. Am. Fish. Soc. 91, 223-224.

Christie, W. J. (1963). Effects of artificial propagation and the weather on recruitment in the Lake Ontario whitefish fishery. J. Fish. Res. Bd Can. 20, 597-646.

Cucin, D. \& Regier, H. A. (1965). Dynamics and exploitation of lake whitefish in southern Georgian Bay. J. Fish. Res. Bd Can. 23, 221-274. 
Davidoff, E. B., Rybicki, R. W. \& Doad, K. (1973). Changes in the population of lake whitefish (Coregonus clupeaformis) in Lake Winnipeg from 1944 to 1969. J. Fish. Res. Bd Can. 30, 1667-1682.

Dryer, W. R. (1964). Movements, growth, and rate of recapture of whitefish tagged in the Apostle Islands area of Lake Superior. U.S. Fish Wildl. Serv. Fish. Bull. 63, 611-618.

Edsall, T. A. (1960). Age and growth of the whitefish (Coregonus clupeaformis) of Munising Bay, Lake Superior. Trans. Am. Fish. Soc. 93, 77-94.

Fenderson, O.C. (1964). Evidence of subpopulations of lake whitefish involving a dwarfed form. Trans. Am. Fish. Soc. 93, 77-94.

Fisher, R. A. (1930). The Genetical Theory of Natural Selection, 272 pp. Oxford: Clarendon Press.

Gulland, J. A. (1969). Manual of methods for fish stock assessment. Part I. Fish population analysis. FAO Man. Fish. Sci. 4, 154 pp.

Hart, J. L. (1931). The growth of the whitefish, Coregonus clupeaformis (Mitchill). Contr. Can. Biol. Fish. 6, 427-444.

Healey, M. C. (1975). Dynamics of exploited whitefish populations and their management with special reference to the Northwest Territories. J. Fish. Res. Bd Can. 32, 427-448.

Healey, M. C. (1978). Fecundity changes in exploited populations of lake whitefish (Coregonus clupeaformis) and lake trout (Salvelinus namaycush). J. Fish. Res. Bd Can. 35, 945-950.

Healey, M. C. (1980). Growth and recruitment in experimentally exploited lake whitefish (Coregonus clupeaformis) populations. Can. J. Fish. Aquat. Sci. 37, 255-267.

Hile, R. \& Deason, H. J. (1934). Growth of the whitefish Coregonus clupeaformis (Mitchill) in Trout Lake, northeastern highlands, Wisconsin. Trans. Am. Fish. Soc. 64, 231-237.

Jensen, A. L. (1971). Response of brook trout (Salvelinus fontinalis) populations to a fishery. J. Fish. Res. Bd Can. 28, 458-460.

Jensen, A. L. (1976). Assessment of the United States lake whitefish (Coregonus clupeaformis) fisheries of Lake Superior, Lake Michigan, and Lake Huron. J. Fish. Res. Bd Can. 33, 747-759.

Jensen, A. L. (1979). Yield per recruit of whitefish (Coregonus clupeaformis) in Northern Lake Michigan. The Michigan Academician, 11, 407-414.

Kennedy, W. A. (1943). The whitefish of Lake Opeongo, Algonquin Park, Ontario. Univ. Toronto Stud. Biol., Ser. 51.62, 23-66.

Kennedy, W. A. (1949). Some observations on the caregonine fish of Great Bear Lake, Northwest Territories. Bull. Fish. Res. Bd Can. 82, 1-10.

Kennedy, W. A. (1953). Growth, mortality, fecundity and maturity in the relatively unexploited whitefısh, Coregonus clupeaformis, of Great Slave Lake. J. Fish. Res. Bd Can. 10, 413-441.

Kennedy, W. A. (1954). Tagging returns, age studies, fluctuations in abundance of Lake Winnipeg whitefish, 1931-1951. J. Fish. Res. Bd Can. 11, 284-309.

Kennedy, W. A. (1963). Growth and mortality of whitefish in three unexploited lakes in northern Canada. J. Fish. Res. Bd Can. 20, 265-272.

Lawler, G. H. (1961). Egg counts of Lake Erie whitefish. J. Fish. Res. Bd Can. 18, 293-294.

Lawler, G. H. (1965). Fluctuations in the success of year classes of whitefish populations with special reference to Lake Erie. J. Fish. Res. Bd Can. 22, 1197-1227.

Miller, R. B. (1947). The effects of different intensities of fishing on the whitefish populations of two Alberta lakes. J. Wildl. Mgmt. 11, 289-301.

Miller, R. B. (1949). Problems of the optimum catch in small whitefish lakes. Biometrics $5,14-26$.

Miller, R. B. (1956). The collapse and recovery of a small whitefish fishery. J. Fish. Res. Bd Can. 13, 135-146.

Mraz, D. (1964). Age, growth, sex ratio, and maturity of the whitefish in central Green Bay and adjacent waters of Lake Michigan. U.S. Fish Wildl. Serv. Fish. Bull.63, 619-634. 
Patriarche, M. H. (1977). Biological basis for management of lake whitefish in the Michigan waters of northern Lake Michigan. Trans. Am. Fish. Soc. 106, 295-308.

Peterka, J. J. \& Smith, L. L. (1970). Lake whitefish in the commercial fishery of Red Lakes, Minnesota. Trans. Am. Fish. Soc. 99, 28-43.

Qadri, S. U. (1968). Growth and reproduction of lake whitefish, Coregonus clupeaformis, in Lac la Ronge, Saskatchewan. J. Fish. Res. Bd Can. 25, 2091-2100.

Ricker, W. E. (1947). Mortality rates in some little exploited populations of fresh water fishes. Trans. Am. Fish. Soc. 77, 114-128.

Roelofs, E. W. (1958). Age and growth of whitefish, Coregonus clupeaformis (Mitchill), in Big Bay De Noc and northern Lake Michigan. Trans. Am. Fish. Soc. 87, 190-199.

Schaffer, W. M. \& Elson, P. P. (1975). The adaptive significance of variations in life history among local populations of Atlantic salmon in North America. Ecology 56, 577-590.

Schoenherr, A. A. (1977). Density dependent and density independent regulation of reproduction in the gila topminnow, Poeciliopsis occidentalis. Ecology 58, 438-444.

Smith, H. T., Schreck, C. B. \& Maughan, O. E. (1978). Effect of population density and feeding rate on the fathead minnow (Pimephales promelas). J. Fish Biol. 12, 449-455.

Spangler, G. R. (1970). Factors of mortality in an exploited population of whitefish, Coregonus clupeaformis, in northern Lake Huron. In (C. C. Lindsey \& C. S. Wood, ed.) Biology of Coregonis Fishes Winnipeg: University of Manitoba Press.

Van Oosten, J. (1939). The age, growth, sexual maturity, and sex ratio of the common whitefish, Coregonus clupeaformis, of Lake Huron. Pap. Mich. Acad. Sci. 24, 195-221.

Van Oosten, J. \& Hile, R. (1947). Age and growth of the lake whitefish, Coregonus clupeaformis, in Lake Erie. Trans. Am. Fish. Soc. 77, 178-249.

Wong, B. \& Whillans, T. (1971). Limnological and biological survey of Hottah Lake, Northwest Territories. Fish. Mar. Serv. Tech. Rep. Ser. CENT-73-6, 1-69.

Wootton, R. J. (1973). The effect of size of food ration on egg production in the female three-spined stickleback, Gasterosteus aculeatus. J. Fish Biol. 5, 89-96. 